\title{
Research on the Talent Training Mode of Food-related Majors in Higher Vocational Institutions \\ Chu Jianwei
}

\author{
Tianjin Modern Vocational Technology College, Tianjin, China \\ xdchujw@163.com
}

Keywords: Profession training package, food-related majors, talent training mode

\begin{abstract}
With rapid expansion of food industry, the demand for talents gets increasingly urgent, and a set of rational vocational skills training standards shall be established. In order to improve the training level of food-related majors, it's important for higher vocational institutions to develop and implement an effective talent training mode for food-related majors. This thesis discusses the development and construction of food-related majors under higher vocational education and the method to upgrade the vocational skills system, and creates a talent training mode of food-related majors in higher education institutions for the purpose of improving the talent training level and social service capabilities continuously, intensifying the demonstration effect continuously and providing reference for talent training of food-related majors to higher vocational institutions.
\end{abstract}

\section{Developing profession training package}

\subsection{Background of food industry}

With the progress of "Beijing-Tianjin-Hebei” integration, Tianjin, relying on its own resource superiority and location advantage, has its modern food industry developing continuously. Many famous transnational enterprises invested and built plants in Tianjin successively to explore the Chinese market. Consequentially, food enterprises in our city now need large-scale equipment, need to establish an international safety management system, need to improve manufacturing of international-standard handicrafts, and need internationalized talents with "craftsmanship" urgently. "Craftsmanship" is a professional spirit, the demonstration of professional ethics, vocational capabilities and professional quality and a professional value orientation and behavioral expression of the practitioners. Thus, for higher vocational education of food-related majors, it's important to establish a set of rational vocational skills training standards and develop an effective talent training mode.

\subsection{Development background of the profession training package}

In order to promote social and economic development of Tianjin and open development of Binhai New Area and accelerate training of high-quality laborers and high-skilled talents, it's essential to improve the vocational training mode based on the existing national vocational standards, integrate and optimize training resources and develop a "professional training package" integrating training standards, guidelines and resources in order to change vocational training from results management to process management, to make training well adapt to the requirements of new techniques, new materials, new equipment, new procedures and the relevant manufacturing posts and to form a standard and rational vocational training system. In order to develop a "profession training package" in line with the national vocational standards and social and economic development requirements, the related enterprises, vocational schools, research institutes and other social powers shall give full play to their respective strength, under government leadership. Thus, the higher vocational institutions shall develop and organize and carry out vocational training in accordance with the "profession training package". 


\subsection{Development of the profession training package for food-related majors}

Tianjin Modern Vocational Technology College (hereinafter referred to as "the College") developed 20 profession training packages for four food-related majors, namely "food inspection", "brewing", "liquor making" and "baking". By developing the packages, the College innovated and improved all the three modules of the four majors. The first is standard package, a set of unified regulations for vocational skills training, which is designed for strict standardization of training pattern, training content, training method, teaching staff, equipment and environment and examination and mainly include five parts, namely vocational standards, training standards, facilities and environment standards, teaching staff standards and evaluation standards. The second is guidance package, a service document for the trainees and teachers to learn and use the "service training package". It provides vocational training, skills identification, job introduction and vocational counseling to trainees, and is also the technical and instructive document for trainers on vocational training organization, teaching and standard management. The guidance package is composed of three parts, occupation guidance, training guidance and evaluation guidance. The third is resource package which contains abundant training resources for the trainees, teachers and training organizations to use. Due to advancement and practicability, the resources can be directly and conveniently used by teachers and can facilitate teachers to apply advanced teaching means. The resource package is composed of three parts, curriculum resources, learning resources and information resources.

\section{Upgrading the vocational skills system and improving the talent training mode of food- related majors in higher vocational institutions}

\subsection{Carrying forward craftsmanship, reconstructing the skills system and enhancing both moral and professional levels of the laborers}

In consideration of the development requirements of professional ethics of the global food industry and the serious situation of food safety in China, the food science professional team of the College was requested to pay equal attention to professional quality and vocational skills and combine political theoretical courses, professional quality courses and professional ethics courses in curriculum. The College paid attention to students' ideological and political education and professional ethics, added food processing professional ethics, food safety management and other content embodying professional education to the training programs, closely combined professional ethics with vocational skills through developing the "profession training package" and reconstructing the vocational skills system, and let the students comprehend socialist core values and the inherent meaning of "craftsmanship". By organizing social practices, volunteer activities and internship in enterprises, the College tries to make the students' technical skills meet the enterprises' requirements and cultivate craftsmen for the food industry with Chinese characteristics.

\subsection{Deepening professional standards improvement, creating a curriculum system and realizing education-training integration.}

In consideration of the poor connection between teaching content and the job skills required by the relevant transnational enterprises, the food science professional team compared the College with similar foreign schools such as Central Institute of Technology, Australia, made an in-depth investigation of the relevant majors, learnt the TAFE Model integrating talent training, specialty construction, curriculum reform and vocational training, made an in-depth comparison between Chinese higher vocational institutions and similar foreign schools in talent training model, curriculum system and teaching conditions, and made a summary. Through interview, teleconference and other ways, the team communicated with the experts of SGS-CSTC Standards Technical Services Co., Ltd, Ting Hsin International Group and some other transnational enterprises, made an in-depth investigation on their job requirements, the international industrial standards and the vocational ability standards. Based on the part of professional standards in the "vocational training package", the team established a comprehensive curriculum system with 
progressive levels and the concept of free choice of study. Moreover, technical experts of enterprises and experts of schools were invited into the professional guiding committee. On premise of analyzing the existing Chinese and foreign vocational ability standards, the "training package" was integrated into the technical training courses. The above efforts laid a solid foundation for development of a set of professional teaching standards for food-related majors.

\subsection{Constructing quality resources jointly, establishing a sharing platform and realizing cloud sharing.}

The training packages for the four types of food-related work contain plentiful study resources. Each package contains a training guidance and a learning guidance for each of the five levels, an examination base containing 5000 questions, 100 model test papers, teaching videos, animation micro-lectures, teaching courseware, etc. For development of the training package, on basis of the resources package, a digital professional teaching resource library that meets the requirements of modern vocational education, enterprise training, further education for employees and popularization and application of new technologies has been set up. A cloud-based resource platform has been established based on quality resources. Depending on remote teaching, smart cloud lecture, computer classroom and other teaching means together with micro-lecture, MOOC, remote lecture and other information-based teaching methods, digital, project-based and internationalized curriculum resources satisfying requirements of students and the specialties have been constructed. In this way, the restrictions of time and space have been broken, and "24-hour" sharing learning has been realized. The team spared no efforts to improve the educational sharing mechanism, realize deep integration of information technology and education, innovate the teaching approaches and learning methods, balance teaching resources and promote development of vocational education.

\subsection{Upgrading the practice base consistent with international standards, and realizing learning-innovation-research-training integration.}

Flowing the international standards, the software and hardware facilities of the practice base has been enhanced, depending on the technological resources of transnational enterprises and research resources of international higher education institutions. In the base, the devices are "internationally common". Thus, an open, influential and international-level practice base integrating the functions of educational reform, entrepreneurial practice, technology research and development and skill training, covering all fields of the food industry such as detection, research and development, GMP and food safety management of agricultural products (food), baked food, functional food and fermentating food has been built. Taking results of scientific research projects as the sources, the base has enhanced the class teaching effects by developing information-based courses and resources integrating teaching, vocational training and technical services. Moreover, the base has established an advanced study and training system with international enterprises. Considering technical innovation, transformation and project introduction requirements of enterprises, the base is able to give technology lecture and training to 3000 people from domestic and foreign food enterprises, cultivate high-end technicians urgently required by the enterprises, hold senior workshops and help staff of enterprises, public institutions and research institutes develop professional perspectiveness. It has won a good reputation.

\section{Results of exploration and practice of new talent training mode}

\subsection{Improving the talent training level continuously}

Through continuous exploration and practice of new talent training mode, the students' ethical standards and professional quality have been enhanced, and the student' socialist core values and professional ethics have been greatly raised. The students won prizes in Tianjin University Students Ideological and Political Open Class Competition. Zhao Ying, an outstanding student graduated from our school won prizes repeatedly in the National Creative Bakery Skills Competition and 
World Skills Competition Qualification Trials, and was employed as practical teacher by a secondary vocational school. She led the students winning prizes and honors on many competitions. Her teaching mode has been used by other schools. Moreover, the students' technical skills and innovation capability have been improved. A student won the gold medal on "2016 Taiwan International Innovative Design Competition”. The college also founded Kiessling Modern College Store together with Tianjin Kiessling Food Co., Ltd. The competition result has been used in "entrepreneurship and innovation”. It became a first-batch Maker Space of Tianjin. Continuous enhancement of the talent training level also embodies in increase of the number of skill certificates acquired by the students and the employment proportion. In the past four years, the proportion of students employed by transnational enterprises was increased by six times. The passing rate of students taking part in international vocational qualification tests such as TAFE certificate, ISO9000 internal auditor, ISO22000 internal auditor, HACCP internal auditor, food inspector and baker reached $90 \%$ on average. 436 students acquired ISO, TAFE and other relevant international vocational certificates. In addition, the College trained 367 non-student trainees, and the passing rate reached $100 \%$. For about 4 years, the employment rate keeps above $98 \%$, and the satisfaction rate of employers is as high as $95.6 \%$.

\subsection{Improving social service capability continuously.}

Through continuous exploration and practice of new talent training mode, the social service capability has been improved continuously. On the one hand, the College deepened technical services for enterprises. In response to the national strategies such as Beijing-Tianjin-Hebei Integration and National Modern Agriculture, the College successfully promoted three technological projects in Yutian County, Hebei Province and other two counties and declared the subject program Otherness Study on Traditional Testing Method of Citrus Juice Content and Fingerprint New Testing Method and Industrial Application in cooperation with Tianjin Shanhaiguan Beverage Co., Ltd. Through the program, the College helped the enterprise get rid of the adulteration and dilution detection problem, improve the product quality and increase its economic benefit. This program filled in the gap in domestic industry. Moreover, in cooperation with enterprises, the College undertook 14 scientific research projects under National Natural Science Foundation of China and won a first prize and a second prize of "Tianjin Scientific and Technological Progress Award”. In addition, the College offered extensive industrial training services. The food science professional team enriched the training programs of professional ethics, professional skills and basic knowledge depending on the training package resources, improved the training forms such as face-to-face instruction, remote education and degree enhancement. By adopting information-based teaching means, the College brought benefits to the staff of Hebei University of Technology, Tianjin Chalton Tomato Products Co., Ltd and Huana Times Testing and Certification Co., Ltd, rural migrant workers, workingwomen, retired soldiers and other groups. Accumulatively, the College trained over 4000 people and made a contribution to industrial restructuring and regional economic development.

\subsection{Intensifying the demonstration effect continuously}

Through continuous exploration and practice of new talent training mode, the specialty construction program set a model for the whole nation. The College organized and finished the higher vocational education improvement program for the major of "food nutrition and detection", the program of teaching resources for higher vocational education for the major of "biological technology and application", the program of "food biotechnology" (a key specialty with financial support of the central government for national model higher vocational institutions) and 12 projects under the higher vocational education innovative development plan of the Ministry of Education and the municipal commission of education. From the above, it can be found that the College has played great leading role. Moreover, as a first-batch national teaching staff training base of Tianjin, since 2012, the College has successfully held three sessions of national core teachers training and offered training for 38 key teachers from 27 western higher vocational institutions including Guangxi Ecoengineering Vocational and Technical College, Lanzhou Vocational Technical College and 
Nanchong Professional Technical College. The College gradually formed teacher brand, specialty brand and industry brand and keeps intensifying its demonstration effect nationwide in education of food-related majors.

\section{Conclusion}

Tianjin vocational training package is a set of professional standards established under national vocational standard framework taking the needs of Tianjin food industry into consideration through adding new content and new requirements such as vocational functions, job content, technical requirements and related knowledge. The profession training packages for "food inspection", "brewing", "liquor making" and "baking" basically contain the core content of the majors of "food biological technologies", "good nutrition and detection" and "food processing techniques". When developing the training packages, the College brought the requirements and characteristics of vocational education into consideration, applied international vision, based on the local industry of Tianjin, upgraded the vocational skills system, innovated the talent training mode of food-related majors in higher vocational education, achieved remarkable results, and provided reference for training of food-related talents to higher vocational institutions.

\section{Acknowledgements}

This research was financially supported by the Tianjin vocational training package ("food inspection”, "brewing”, "liquor making” and "baking”).

\section{References}

[1] Li Ru. Functional Analysis and Building Basic Framework of Occupational Training Packages, Higher Vocational Education (Journal of Tianjin Vocational Institute), 2012, 21 (06):10-13.

[2] Mi Jing. Review of Australian national training package system, Education and Vocation, 2005, 02: 49-52.

[3] Chen Lingwei, Chen Lingrui. Comparative analysis of the Australian training package and China's professional training program, Management \& Technology of SME, 2013, 04: 191-192. 